\title{
Distribution of silty fraction and slurry by profile of arable soils of the central forest-steppe
}

\author{
Elena Kovalyova*, Ekaterina Kotlyrova, Sergej Linkov, and Olga Kuzmina \\ Belgorod State Agrarian University named after V. Y. Gorin, Belgorod, Russia
}

\begin{abstract}
The work is devoted to the study of granulometric composition of soils of 120-year and 240-year agricultural development of meadowsteppe landscape on the example of Belgorod region. In the lateral distribution of the silt fraction contained in the arable horizon, a significant increase in its proportion in the lower parts of the soil catenas of the 120year arable, for the 240-year arable the lateral variations of the silt fraction are less noticeable. The averaged values of silt content over slope profiles of 240-year arable land showed local maximum of silt confined to subsoil horizon. An inverse relationship was found for slopes on 120-year-old arable land, namely the fact that the percentage of silt fraction increases at depth does not lead to an increase of the same fraction in the subsoil layer. Numerous blindfolds were found in the soil sections studied by caten, especially many of them were detected at a depth of up to one meter. Average area occupied by mole crusts on the walls of averaged transects is $80-90 \%$ on the 120 -year arable and $70-80 \%$ on the 240 -year arable. On soils of background catenas, $30-40 \%$ of the walls of soil transects are occupied by mole-rats. Blistergrasses are more often found in soils of catens of northern exposition - both 120year and 240-year arable land.
\end{abstract}

\section{Introduction}

Anthropogenic impacts on soils have strongly increased in the last century and are a new frontier in the research aspects of soil science [1]. A large number of theoretical and methodological developments in this area are a characteristic feature of modern soil science [7]. The study of changes in soil properties during their agricultural development is relevant both for the purposes of genetic soil science and for assessments of the ecological condition of forest-steppe landscape components. Agrochronoradograms of soils with different age of agricultural development allow us to reveal not only the nature of changes in soil properties, but also to detect the staging of these changes, to reveal the features of transformations at the early and late stages of plowing, to reveal the rate of loss or accumulation of some substances in soils.

In the process of agrogenesis in arable soils there is an accumulation and then consolidation of new features and properties that are not characteristic of natural soil formation. Therefore, there is a need to study the direction, stadiality, mechanisms and regularities occurring in agrogenic soil bodies over time [18]. Comparative analysis of the

*Corresponding author: umat_05@mail.ru 
properties and processes of soil formation on arable lands of different ages is known as the method of soil agrochronorads $[8,17,19,20]$.

A very great influence on rainwater absorption by soil on slopes has an agrotechnical effect. The essence of agrotechnical measures on slopes is reduction of slope runoff. Ploughing across the slope reduces spring runoff by about 3 times compared to longitudinal ploughing. The degree of moisture redistribution is influenced by the exposure, length and shape of slopes, as well as the amount and intensity of precipitation [9].

Soil fertility is largely determined by its physical and chemical properties. The reaction of the soil environment according to the totality of system relations is considered as one of the leading properties. It determines the direction and intensity of almost all soil processes, providing nitrogen, phosphorus and potassium regimes, as well as the availability of nutrients, including trace elements. Despite the fact that the chernozem soils of the Central Black Earth Region (CCR), occupying $70.7 \%$ of its territory, are among the most fertile in Russia, they are, at the same time, largely subject to various types of degradation $[2,12,21$, 22 ].

It is known that physiographic zoning of territories is based on the system of relationships between soils and soil-forming factors, among which climatic conditions play the leading role. At that, the difference between precipitation inflow and evaporation has the greatest influence on profile formation [10,11]. Factors of anthropogenic influence weaken or enhance the natural processes, which, nevertheless, remain dominant. Since total runoff is one of the main specific factors of soil evolution with direct and independent impact, the observed trends of climatic conditions change [13] can shift the dynamic equilibria in soils as well.

The content of silt fraction in microaggregate analysis reflects the genetic features of the soil and the results of anthropogenic impact on them, and the different relationships between the content of silt fraction in microaggregate and mechanical analysis serve as a reliable indicator of the physical condition of soils and has been successfully used for over 50 years to assess the conditions of aggregate formation to stability of soil structure. [4].

Pedoturbation activity of soil mammals leads to the formation of a complexly organized spatial soil structure, which combines mechanically stable structures with gaps occupied by less dense soil mass. This organization of the soil body has a favorable combination of the properties of the solid and less solid soil masses. An important feature of this organization is the long-term positive effect of mammalian pedoturbation activity on other ecosystem components (soil invertebrates, microorganisms and plants).

Soil burrows of mole rats are characterized by lower electrical conductivity than the surrounding soil at times, due to changes in soil density and moisture compared to undisturbed soil. The magnitude of the effect of mole vole swarming activity on soil electrical conductivity is not limited to the geometric boundaries of the pores. The pores are surrounded by a halo with a radius of $1.0-1.5 \mathrm{~m}$, which is characterized by increased soil electrical conductivity. The size of the halo increases with the age of the pores and with their more aggregated mutual arrangement $[5,6]$.

Mole swarming activity has a complex effect on soil, vegetation, soil animals, activity of microbiological processes in soil. In most works, the nature of pedoturbation influence of animals is studied in the "influence - control" format. However, the results of the impact have a complex spatial dynamics, which changes over time. The nature of the impact of swarming activity can be fully revealed only in the context of spatial assessment of the dynamics of ecosystem processes induced by pedoturbation activity $[3,14,15,16]$. 


\section{Materials and research methods}

For site selection we needed materials of the Russian State Archive of Ancient Acts (RGADA, Moscow), on the basis of which the age of tillage of the soils studied caten in the meadow-steppe key research area was established. The age of tillage was 120 years and 240 years.

The field study of soils at the selected key sites involved the following types of work: laying of soil sections, description of the soil profile structure, photographing of the front walls of soil sections, determination of soil density using steel rings; taking soil samples for laboratory analyses.

As a result of field studies, 32 transects in the meadow-steppe area were studied (6 transects on background catens and 12 transects on plowed catens each). Each transect was provided with layer-by-layer values of morphometric indicators of soil horizons and the depth of carbonate occurrence. Soil laboratory analysis methods included determination of the granulometric composition (including silt fraction content) by the Kachinsky method. A total of 321 samples from the Kurasovka site were analyzed.

The key study area named "Kurasovka", corresponding to the meadow-steppe forest-steppe landscape, is located on arable lands to the south-east of Kurasovka settlement of Ivnyansky District, and the background areas are in the vicinity of Safonovka and Pokrovsky settlements of the same district of Belgorod Region.

In the catenas identified for the study, the average length of the slopes was $500-550 \mathrm{~m}$. They are convex in shape and have steepness from $0-2^{\circ}$ at the top to $4-6^{\circ}$ at the bottom. On each of the four ploughed shores (two polar exposures of 120 and 240 years of ploughing age) 6 soil transects were laid. All the points of these transects on each catena were chosen on the assumption that they would have positional analogues on the opposite slope and on the slopes of the catena of a different ploughing age.

Three transects were created on the two background catens of northern and southern exposures, the top of which corresponded to a completely flat watershed (a close analog of the locations of transects 1 and 2 on arable land), the middle transect corresponded to the positions of transects 3 and 4 on arable land, and the lowest transect corresponded to the locations of transects 5 and 6 in the lower parts of the studied slopes on arable land. The distance between the studied profiles of the soils of the background rims was $180-200 \mathrm{~m}$. The limitation of the study points of the background rims was determined by weather conditions of the study period, which did not allow us to study them in detail (by laying 6 soil transects on each background rims).

The background areas of the studied meadow-steppe landscape soil catenas are characterized by the following features of the morphological structure of soil profiles.

In the catena of northern exposition from watershed to lower part of the studied slope there is a regular change of soils by relief elements.

At point 1 with a surface steepness of 0 degrees, the soil is identified as typical black earth; thick, medium-loam, on carbonate medium loess-like loam (Fig. 1A).

Typical black earth; thick, medium-loam, on carbonate medium loess-like loam was studied at point 2 in the area with a $2-3^{\circ}$ steepness of the surface. The width of the watershed plateau-like area between the side slopes of the escarpment is $30 \mathrm{~m}$.

The next, lowest transect in the background area was laid on the surface with a steepness of $5-6^{\circ}$. The soil surface is covered with steppe felt. The soil is typical carbonate low-powered, medium-loamy chernozem on carbonate medium loess-like loam.

The transects in the Kurasovka background area of the southern exposure are analogous to those of the northern exposure in terms of the morphological characteristics of the slope (Fig. 1B).

Section 1. Watershed surface with steepness of about $1^{\circ}$. Soil surface $0+4 \mathrm{~cm}-$ rags of stems and leaves of herbaceous plants, loose, dry, covering $80-90 \%$ of soil surface area, 4-year old, plant stems charred in places. Soil: Typical, moderately thick, close to thick, moderately loamy, on lowpowered medium carbonate loess-like loam. 
A

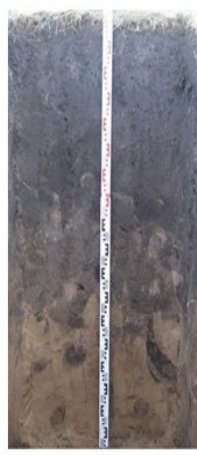

1

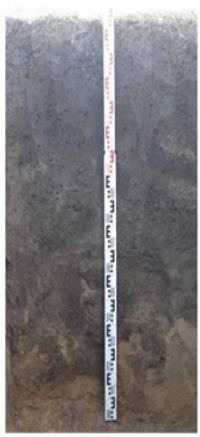

2

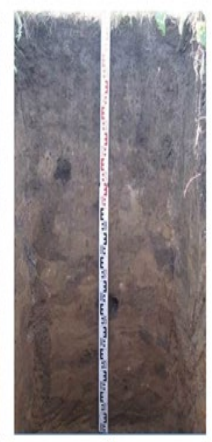

3
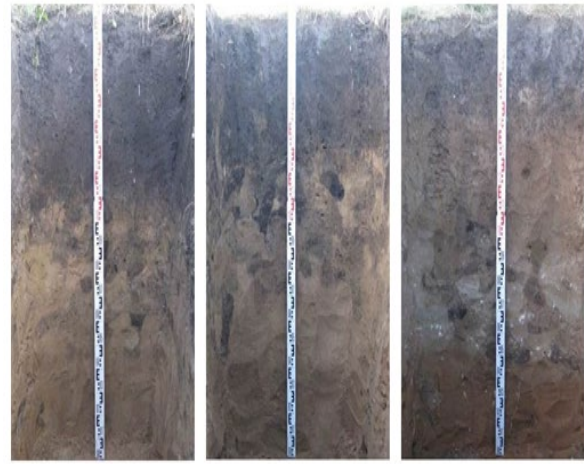

Fig.1. Photographs of soil profiles in the Kurasovka meadow-steppe landscape background area of northern (A) and southern (B) exposures.

Section 2. Point on unploughed southeastern exposition slope, steepness less than 20. Frequent fresh outbursts of burrows. Felt $+3 \mathrm{~cm}$, dry, predominantly Tipchak, soil surface coverage - about $60 \%$. Soil: typical, medium-deep, medium-loamy chernozem on medium carbonate loess-like loam.

Section 3 is laid on the slope with surface steepness of 5-6 . Fragmentary boil-up on slopes starts from $72 \mathrm{~cm}$ depth, continuous - from $86 \mathrm{~cm}$ depth, rapid - in 96-135 cm layer, deeper the boil-up weakens. At the depth of $155 \mathrm{~cm}$, boiling becomes fragmentary and weak. Soil is leached chernozem, thin, soil-gleyey, on heavy carbonate clay loam underlain by gleyed mottled sandy loam heavy clay loam.

\section{Results and their discussion}

The initial heterogeneity of soil-forming rocks contributes to the radial distribution of granulometric composition. In the background areas, gradual weighting with depth is detected due to increase in the proportion of silty fraction, which may be due to the presence of light clayey bedrock, replacing closer to the surface by less heavy brown carbonate loams.

Granulometric composition on the plot with arable soils is homogeneous along vertical profile of soils. On this background the processes of movement of silt fractions in the upper part of profile, arising due to agro-lesivage, are noticeable. Thus, the averaged values of silt content along the slope profiles of the 240-year arable land allow us to identify a local maximum of silt confined to the subsoil horizon (Fig. 2), which indicates the action of the above-mentioned process.
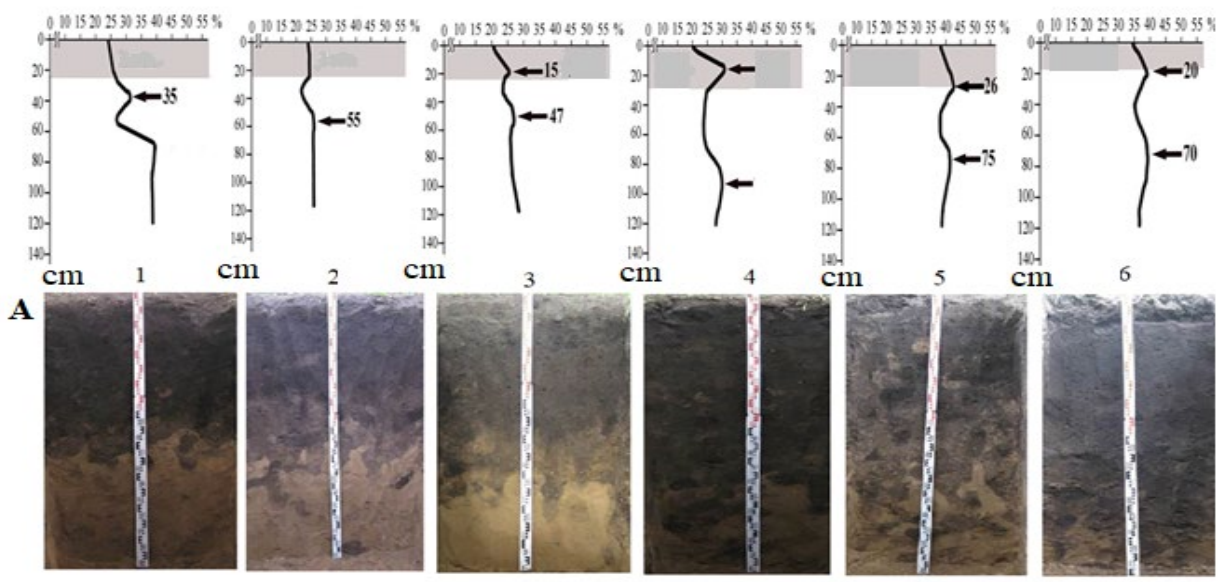


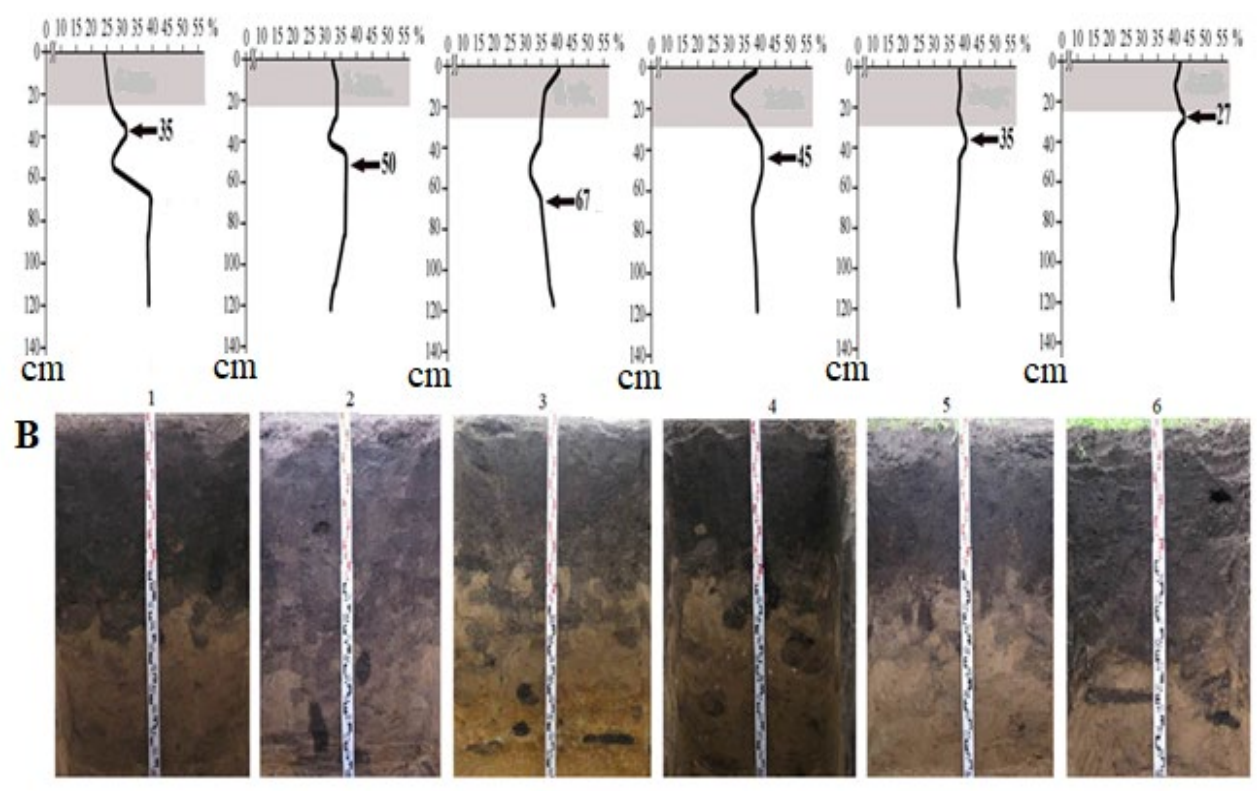

Fig. 2. Silt content in soil profiles of caten soils of northern (A) and southern (B) exposures of 120year arable land (Kurasovka).

This process is found on both northern and southern slopes. For arable land of 120 years of age, local subsoil maximum of silty fraction is not statistically expressed. Probably, longer period is necessary for manifestation of results of partivation process (loessivation) on arable lands.

In the lateral distribution of the silty fraction contained in the arable horizon, a significant increase in its proportion in the lower parts of the soil catenas of the 120-year-old arable soil is found.

For 240-year arable land lateral variations of silt fraction are less noticeable. The lateral distribution of silt fraction (and changes in the overall grain size distribution) can be affected by erosion-accumulative processes, in case of non-uniform radial distribution of fractions. If the lower soil layers are enriched with silt fraction, intensive flushing will result in increase of its content in the arable horizon, and vice versa.

In the case of the arable land studied, an inverse relationship was found for the slopes on the 120 -year-old arable land, namely that the fact that the percentage of the silt fraction increases at depth does not result in an increase of the same fraction in the tillage layer.

In the soil sections studied by caten, we detected numerous gadflies and burrowing passages. Especially many of them were detected at a depth of up to one meter, which is often reflected also in the minimum soil density at this depth. The average area occupied by mole cranes on the walls of the averaged transect is $80-90 \%$ on the 120 -year-old arable and $70-80 \%$ on the 240 year old arable. Moreover, mole rats did not leave as many tracks in the background katches as in the arable fields (Fig. 3). According to the averaged characteristic, only $30-40 \%$ of soil transect walls were occupied by mole cranes in the background. 

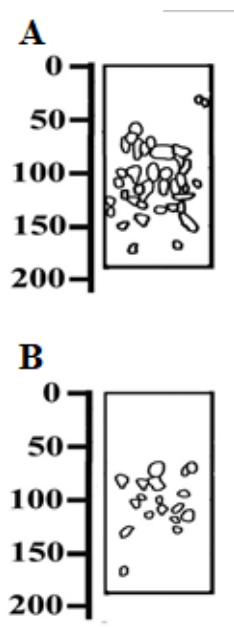
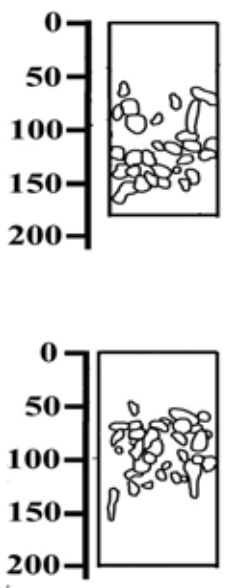


Fig. 3. Emphasized on the front walls of the soil transects of the background molehill trees: A - northern exposure, B - southern exposure.

In the 120-year old and 240-year old arable fields (Fig. 4-5), we detected a tier structure in the distribution of gadfly passages. The upper, less representative tier reaches a depth of $50 \mathrm{~cm}$. The minimum number of burrowing mole holes was recorded here, which, among other reasons, may be related to the difficulty of identifying burrowing holes in the dark gray homogeneous thickness of humus horizons. Only in the middle of the slope of the northern exposition on old-age arable land, gadfly outcrops are clearly distinguished in this layer. The second tier was recorded at a depth of $50-60 \mathrm{~cm}$, where the mole vole is most active.

A

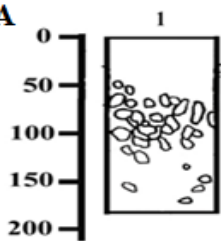

B

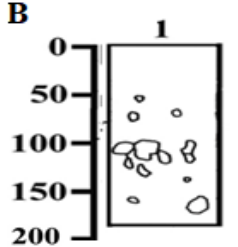

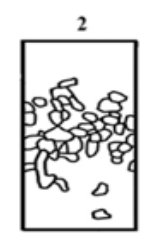
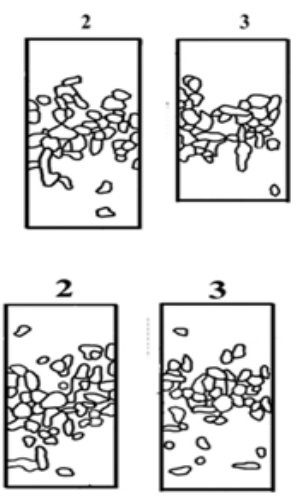

3

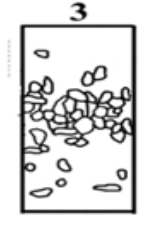

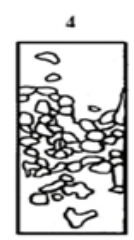
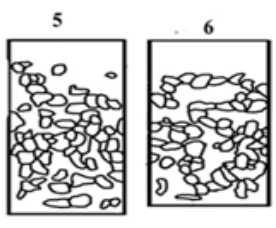
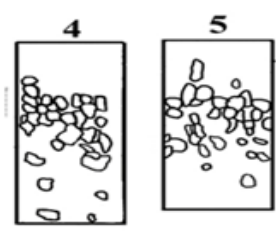

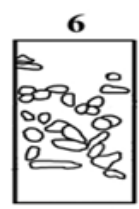

Fig. 4. Induced molehills on forewalls of soil transects of 120-year-old arable land: A - northern exposure, B - southern exposure. 


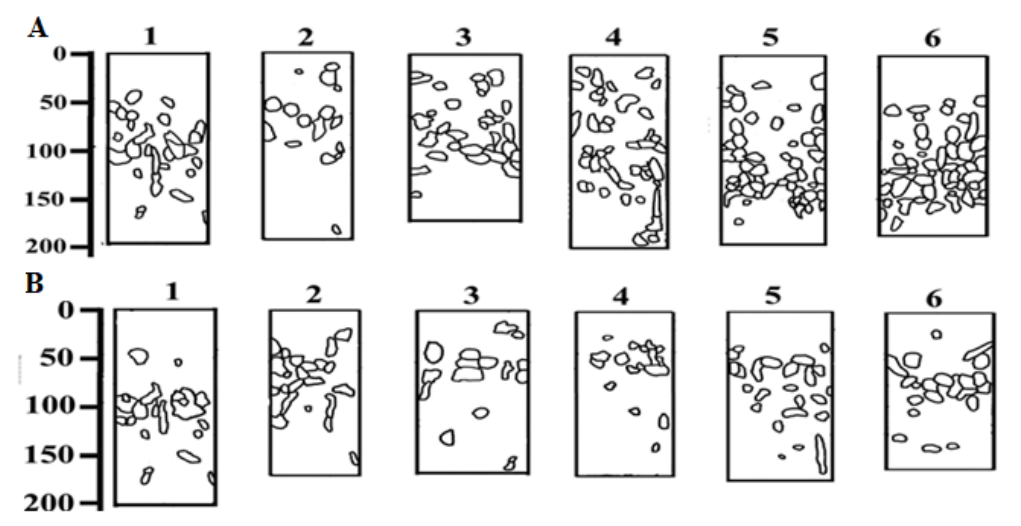

Fig. 5. Emphasized molehills on forewalls of soil transects of 240year arable land: A - northern exposure, B - southern exposure.

It is at this depth that it carries out its main vital activity, and also at this depth it is easier to identify gadflies, because there are very few other influences on the soil that could place it in a position to be identified. Here the passages are much more distinct and numerous than on the sub-surface soil layer of $0-50 \mathrm{~cm}$.

\section{Discussion}

In granulometric composition of different-age arable soils silty fraction strongly prevails. For example, on the background plot at a depth of more than $60 \mathrm{~cm}$ it reaches $50 \%$ of the content of all the distinguished fractions. Growth of silt fraction is also observed up to depths of 160 and even 200 $\mathrm{cm}$, which cannot be explained only by change of profile character of the indicator caused, among other reasons, by silt illuviation. Probably, in the researched soils the influence on granulometric composition is rendered also by soil-forming rock, in which structure silt and dust fraction are in great degree present. At the same time, a more regular (with a gradual growth gradient) pattern of silt distribution across the soil profile is observed in the forest than on ploughed catenas.

Radial distribution of individual granulometric fractions reveals dependence on the type of land use and duration of ploughing. It leads to smoothing of radial differentiation of granulometric composition; in particular, the amount of silty particles in arable horizon increases due to homogenization of upper sandy sub-horizons with underlying, less silt-poor ones. In the 240-year arable soils the alignment of silt profile distribution is even more pronounced. In the latter case, spatial heterogeneity of the granulometric composition is strongly expressed, probably associated with the increasing influence of zoogenic processing of soil profiles (mole-rats) (Fig.6). 

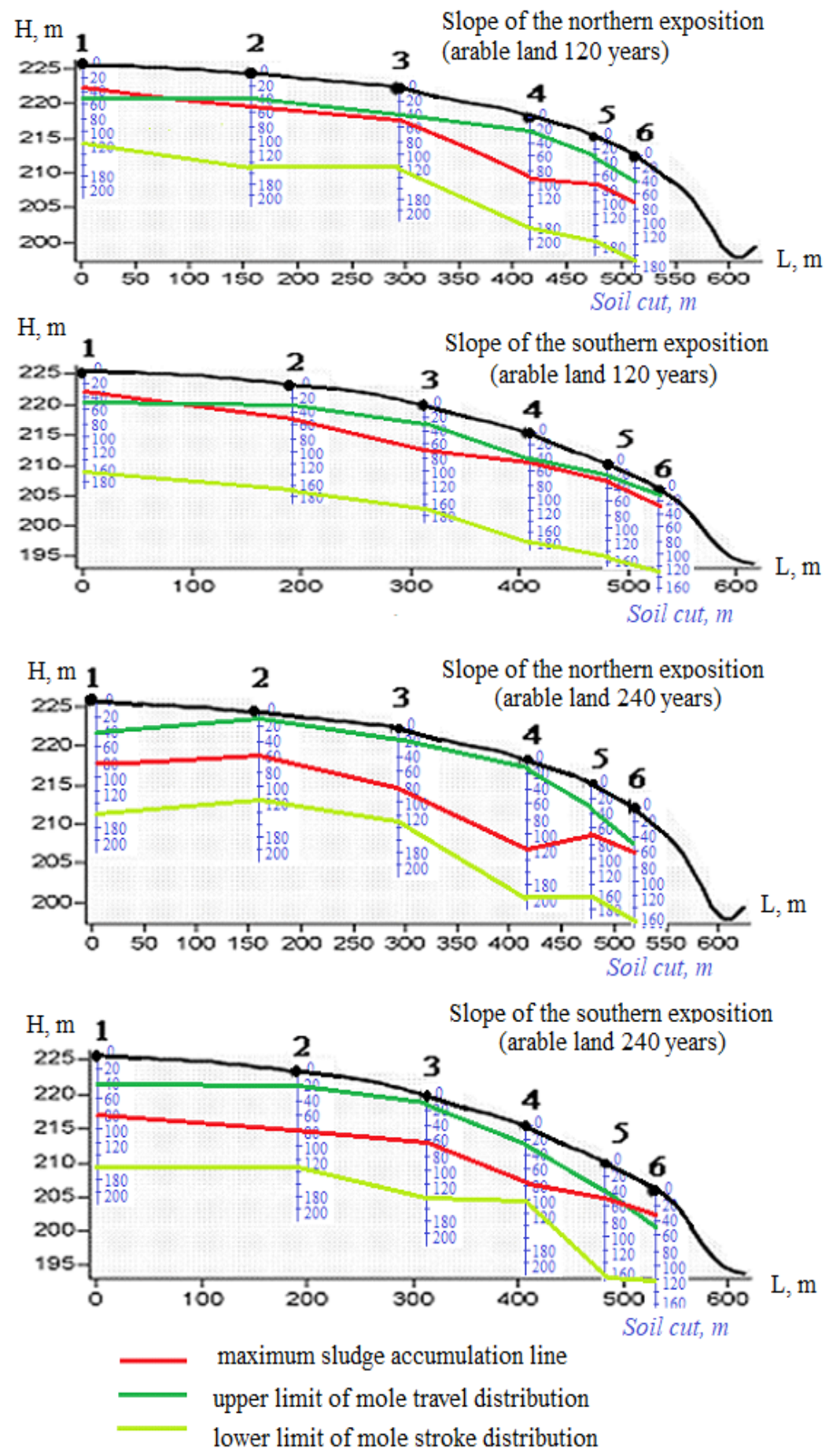

Fig.6. Distribution pattern of silt and sludge with regard to topography on 120-year and 240-year arable land. 


\section{Conclusion}

The granulometric composition of soils of the study area is light clayey (57\% of samples) and heavy loamy ( $41 \%$ of samples).

Among the fractions, silty (35\%) and coarse dust (35\%) predominate in the average case, while fine $(15 \%)$ and medium $(10 \%)$ dust occurs in smaller amounts. The soils of the background area of the southern exposition are distinguished by a higher content of fine sand, the other areas are close by the fractional ratio.

A large number of gadwall were also noted in the study area. It was noted that mole rats are more often found in soils of catens of northern exposure slopes - both 120-year and 240year ploughland. We explain this by the more favorable forage base of plant root systems formed on slopes of northern exposition, which are more moistened. At the same time, the percentage of coverage of the transect by mole rats is extremely high exactly in the lower parts of the slopes of these catens, which receive the maximum amount of moisture.

\section{References}

1. A.L. Alexandrovsky, E.I. Alexandrovskaya, Soil evolution and geographic environment, 223 (Moscow, Nauka, 2005)

2. A.V. Akinchin, L.V. Levshakov, S.A. Linkov, V.V. Kim, V.V. Gorbunov, Bulletin of the Kursk State Agricultural Academy 9, 16-21 (2017)

3. A.F. Vadyunina, Z.A. Korchagina, Methods of research of physical properties of soils 416 (Moscow, Agropromizdat, 1986)

4. K.K. Gedroyts, Journal of Applied Chemistry 2 (3-4), 16-24 (1929)

5. A.V. Zhukov, T.M. Konovalova, Visnikof Dnipropetrovsk University Biology Medicine 2 (2), 33-40 (2011)

6. A.V. Zhukov, O.N. Kunah, T.M. Konovalova, Biological Bulletin of Melitopol State Pedagogical University 3, 13-27 (2011)

7. I.V. Ivanov, Yu.G. Chendev, Evolution of soils and soil cover Theory, diversity of natural evolution and anthropogenic soil transformations, 456-469 (Moscow, GEOS, 2015)

8. F.I. Kozlovsky, Theory and methods of studying soil cover 398 (Moscow, GEOS Publisher, 2003)

9. E. Kotlyarova, V. Grisina, S. Litsukov, A. Stupakov, E3S web of Conferences, 254, 05006 (2021) https://doi.org/10.1051/e3sconf/202125405006.

10. E.G. Kotlyarova, I.A. Kazanbekov, A.I. Titovskaya, IOP Conference Series: Earth and Environmental Science, 624, 012228 (2021) doi:10.1088/1755-1315/624/1/012228.

11. E. G. Kotlyarova, A.I. Titovskaia, A.V. Akinchin, M.N. Riazanov, Modern Applied Science 9 (3), 80-90 (2015)

12. S.A. Linkov, A.V. Akincin, I.S. Donchenko, A.A. Popov, News of science in the agroindustrial complex, 2-2 (11), 16-19 (2018)

13. S.A. Linkov, A.V. Shiryaev, A.V. Akincin, L.N. Kuznetsova, Innovations in the agroindustrial complex: problems and prospects 4 (24), 211-219 (2019)

14. A.E. Pakhomov, T.M. Konovalova, A.V. Zhukov, Bulletin of the Dnipropetrovsk University. Biology, Ecology 18-1, 58-66 (2010)

15. A.E. Pakhomov, G.I. Tyrygina, Mammals. Theses of reports of the III Congress of AllUnion Theriol. 1, 267-268 (1982) 
16. A. E. Pakhomov, A. F. Pilipenko, V. L. Bulakhov, On the possibility of using mammal swarming activity for targeted formation of soil mesofauna in the areas of forest land reclamation, Biogeocenotic studies of forests of man-made landscapes steppe zone of Ukraine, 167-175 (DSU, 1989)

17. O.A. Skryabin, Structure of soil cover, methods of its study, 207-209 (Perm, PGSKHA, 2007)

18. Yu.G. Chendev, A.N. Gennadiev, Bulletin of Moscow University. Geography 5, 30-39 (1993)

19. Yu.G. Chendev Evolution of forest-steppe soils of the Srednerusskaya Upland in the Holocene, 174 (MOSCOW: GEOS, 2008)

20. Y.G. Chendev, A.N. Gennadiev, A.P. Zhidkin, T.S. Koshovskii, I.Y. Koshovskii, Distribution of organic matter in soils of forest-steppe caten of different terms of agricultural development, 274-280 (Vagurin, E.A. Zazdravnykh. - Belgorod, 2017)

21. S. D. Litsukov, E.G. Kotlyarova, S.A. Linkov, L.N. Kuznetsova, T.S. Morozova and A.V. Shiryaev, IOP Conference Series: Earth and Environmental Science, 839 (2021)

22. S D Litsukov, E G Kotlyarova, L N Kuznetsova, A V Akinchin1, S A Linkov, IOP Conference Series: Earth and Environmental Science, 677 (2021) 